\title{
Mesentery System is a Section of Meraque System in Persian Medicine
}

Abstract

Recently an article about Mesentery system, in journal of Lancet Gastroenterology Hepatol has been published which has many conflicts with what is called Meraque System in Persian Medicine. This system is an ignored system or organ in medicine which has many roles in health and disease of human body. In this commentary we try to point to these strength and weakness and conflicts.

Keywords: Persian medicine; Meraque; Mesentery system; GI; Peritoneal cavity

\section{Introduction}

\section{History}

Although article Mesentery system [1] was remarkably written and informative, it needs some commentaries. The oldest reference of mesentery system article [1] refers to 300 years ago $[2,3]$ whereas Persian Medicine (PM) as a virtual School of Medicine with circa 3000 years antiquity, considered it as Meraque [4]. Essentially this system is such complicated, that nobody could ever completely distinguish its details [1]. Meraque System has nearly 6 labyrinths which Mesentery is one of them (although it is the most important), yet it cannot do all functions alone. There has to be other parts involved that need to be explained. Since 2008, our studies lead to 7 publications and workshop.

One common point is the disagreement of Mesentery terminology [2,3,5] and Meraque system [4] amongst scholars. We concluded that in some eras, some labyrinths are forgotten or focused, or vice versa. Meraque System aims to suggest a multilayer and unified system that will be the first one in this regard.

\section{Tracing our theory}

"Discrete entity", "Mesenteric contiguity" [6], "intestine and mesentery contiguity from the diaphragm to the pelvic floor" [7], "mesentery and related structure" [3]"mesentery is between the body system and the intestines" [7] all showing the system as a section of a multi-section organs. Absence of organ boundary in your system will be defined in Meraque System. In addition a mapping for Mesentery System is needed $[6,8]$ including the organ beginning and ending, which is not introduced in yours.

\section{The Map of System}

The map is useful for gastrointestinal tract (GIT) specialist, treating with less side effects. It can justify cancer metastasis, via contiguity [9]. The most cancers of LI can metastasize to superior organs [10]. Why \& how mesentery can attack thoracic cavity,

\author{
Mini Revew \\ Volume 8 Issue 5 - 2017 \\ Avijgan Majid* and Avijgan Matab \\ Professor of Infectious Disease and Traditional Persian \\ Medicine, Isfahan University of Medical Sciences, Iran \\ *Corresponding author: : Avijgan Majid, Professor of \\ Infectious Disease and Traditional Persian Medicine, Isfahan \\ University of Medical Sciences, P.O.Box 795, Alzahra Hospital, \\ Soffe St, Isfahan, Iran, Tel: +46 7611962 85; \\ Email: avijgan@yahoo.com
}

Received: August 16, 2017 | Published: September 13, 2017

while being closed up to the diaphragm [7]. Meraque theory indicates a connection between thorax and abdomen. What we follow in our theory is the discussion about this map.

\section{Embryologic Evidence}

Essentially, Meraque system has six defined labyrinths and is adopted from determined area; root region or abdominal posterior core point [1]. These six layers can be Meraque (posterior Fascia overlying posterior wall), and 5 more labyrinth. PM has mentioned Serousa [8] and (Toldt's Fascia too, but in Persian name), which are made embryologically layer to layer (Unpublished data).

\section{Other Evidence for Meraque System}

Despite separation of mesentery, intestine and posterior wall, they have contiguity [3,6-8]. "Entirety of system", "posterior abdominal core" [11] and "entire mesentery as extra retroperitoneal" [12] clearly demonstrate believing in a separated system and approves Meraque System. All are showing separated sections that may be adopted from Meraque labyrinth in the posterior wall. This is one of the most important reasons that prove our theory.

\section{Conflict on Keywords}

The article's keywords may not cover the history of ancient Medicine references [12]. Moreover, if the search was carried out in other languages and medicines such as Persian Medicine, you would had certainly more review articles. I recommended reviewing the keywords in our articles too, which fasciology is one of them. (Personal Communication in personal researchgate profile which this is still remained non-responded0. 


\section{Mesenteric Sciences}

This prevent inconsistent theories [2,3,5], by gathering all existing theories from 2000-3000 years ago till now that leading to a harmony on different names of system $[7,8,13,14]$.

I would gladly consider collaborating by sharing ideas and coming into a common view (Firstly, studying our articles to understand the basic concept of Meraque).

\section{One Suggestion}

If the Meraque System is verified and all 6 labyrinths are found as scientific findings, this may be effective in many medicinal fields.

At the moment peritoneal and rectal ozone therapy is used in which ozone $\left(\mathrm{O}_{3}\right)$ can reach the Meraque system through mesentery system, and then spread to the whole body, affecting greatly [15]. Actually, the relationship of some hematologic, immunologic, endocrine, metabolic diseases and else in regard to mesentery system are under study $[8,16]$. We strongly and accordingly insist that the $\mathrm{M} / \mathrm{S}$ has a critical role in the body, through which we can reach many areas in the body [4].

\section{Other Conflicts}

There are more conflicts between us on Toldt's Fascia, histology, adiposity, location of Pancreas, connection between system and intestine which named serousa (and Rizesh or Ensebab which is a mysterious term in PM), but there is not enough place to be explained (unpublished data).

Mesentery system can be a section of a more extended organ in Persian Medicine (PM) which is called Meraque. Based on scattered information in PM it has six labyrinths and includes all membrane, Fascia, vessels, adiposity and gut. In PM, it has very important role in health and diseases.

\section{Acknowledgment}

Hereby we Thank Dr Mahmoud Babayeian and Dr Maryam Yavari for their valuable comments.

\section{Conflict of Interest}

There is not any conflict of interest.

\section{References}

1. Coffey JC, O'Leary DP (2016) The mesentery: structure, function, and role in disease. Lancet Gastroenterol Hepatol 1(3): 238-247.
2. Coffey JC, Dillon M, Sehgal R, Dockery P, Quondamatteo F, et al. (2015) Mesenteric-based surgery exploits gastrointestinal, peritoneal, mesenteric and fascial continuity from duodenojejunal flexure to the anorectal junction-a review. Dig Surg 32(4): 291-300.

3. Sehgal R, Coffey JC (2014) Historical development of mesenteric anatomy provides a universally applicable anatomic paradigm for complete/total mesocolic excision. Gastroenterol Rep 2: 245-250.

4. Avicenna (1987) Canon of Medicine, Teheran. In: Muhhamad Majed Abdolrahman Sharafkandi \& Muhhamad Majed Mahroukh (Eds.), $4^{\text {th }}$ edn), Sourosh Publication, Iran.

5. Culligan K, Coffey JC, Kiran RP, Kalady M, Lavery IC, et al. (2012) The mesocolon: a prospective observational study. Colorectal Dis 14(4): 421-428.

6. Culligan K, Walsh S, Dunne C, Walsh M, Ryan S, et al. T(2014) The mesocolon: a histological and electron microscopic characterization of the mesenteric attachment of the colon prior to and after surgical mobilization. Ann Surg 260(6): 1048-1056.

7. Coffey JC, Culligan K, Walsh LG, Sehgal R, Dunne C et al. (2016) An appraisal of the computed axial tomographic appearance of the human mesentery based on mesenteric contiguity from the duodenojejunal flexure to the mesorectal level. Eur Radiol 26(3): 714-721.

8. Boni L, Benevento A, Dionigi G, Rovera F, Diurni M, et al. (2005) Injection of colorectal cancer cells in mesenteric and antimesenteric sides of the colon results in different patterns of metastatic diffusion: an experimental study in rats. World J Surg Oncol 3: 69.

9. Riihimäki M, Hemminki A, Sundquist J, Hemminki K (2016) Patterns of metastasis in colon and rectal cancer. Sci Rep 6(36): 29765.

10. Oliphant M, Berne AS (1982) Computed tomography of the subperitoneal space: demonstration of direct spread of intraabdominal disease. J Comput Assist Tomogr 6(6): 1127-1137.

11. Dodds WJ, Darweesh RM, Lawson TL, Stewart ET, Foley WD, et al. (1986) The retroperitoneal spaces revisited. Am J Roentgenol 147(6): 1155-1161.

12. Walsh LG, Kenny BJ, El Bassiouni M, Coffey JC (2016) Cancer arising from the remnant mucosa of the ileoanal anastomosis leading to pouchectomy. BMJ Case Rep pii: bcr2015212802.

13. Healy DA, Murphy SP, Burke JP, Coffey JC (2013) Artificial interfaces ("AI") in surgery: historic development, current status and program implementation in the public health sector. Surg Oncol 22(2): 77-85.

14. Di Filippo C, Capuano A, Rinaldi B, Luongo M, Lettieri B, et al. (2011) Intraperitoneal Oxygen/Ozone Treatment Decreases the Formation of Experimental Postsurgical Peritoneal Adhesions and the Levels/ Activity of the Local Ubiquitin-Proteasome System. Mediators Inflamm 2011: 606718.

15. Batra A, Heimesaat MM, Bereswill S, Fischer A, Glauben R, et al. (2012) Mesenteric fat-control site for bacterial translocation in colitis? Mucosal Immunol 5(5): 580-591. 